\title{
Livelihood Diversification Scenario in Hill State, Meghalaya: Impact and Determinants
}

\author{
A. Dympep", R.J. Singh, Ram Singh and S. Chiphang \\ School of Social Sciences, College of Post-graduate Studies, Central Agricultural University, Umiam, Meghalaya-793103, India \\ *Corresponding author: aletheadympep@gmail.com
}

\begin{abstract}
Livelihood diversification is a norm in every economy, particularly in rural India, where farming alone rarely provides sufficient income. The study was conducted at Mawpran village in the hilly terrain, Meghalaya, India in the year 2017, with the objective to analyze the extent of livelihoods diversification among rural farm families, the impact of livelihood diversification and its determinants. Ninety respondents were selected by simple random sampling. The study found that majority of the farmers diversified from on-farm traditional crops to on-farm high-value crops (strawberry) while a majority of landless respondents had to do diversifying livelihood activities. Using the Wilcoxon sign rank test, it was observed that diversification had a significant impact on material possession and income level of the respondents. Diversification index was measured with the help of Simpson Diversification Index (SDI) and it conferred that fifty percent of the respondents belong to the high level of diversification (more than 0.43 ) and the average diversification index of the respondents was 0.32 which implied that the majority of the respondents had diversifying livelihood activities. Variables like education and cosmo-politeness were found to be significantly related to their degree of livelihood. Thus, diversification of livelihood is an important feature of rural survival and improving income level.
\end{abstract}

Keywords: Livelihood diversification, impact, determinants, Simpson Diversification Index

Agriculture is the predominant activity for most rural households in India although the relative importance of crop cultivation has decreased. In 2013-2014, an estimated growth rate in economic activities in agriculture, forestry and fishing was only 2.7 per cent while there was significant growth in non-farm activities like business service, hotels, etc. (NSSO, 2014). The agricultural sector is characterized by decreasing farm sizes, low levels of output per farm, low productivity, a high degree of subsistence farming, with increases in production being driven mainly by area and not yields growth (Jirström et al. 2011). As a result, rural households are forced to look towards alternative sources of income. In India, land-based livelihoods of small and marginal farmers are increasingly becoming unsustainable, since their land is no longer able to meet the requirements of food for the family and of fodder for their cattle (Hiremath, 2007).
Diversification is the single most important source of poverty reduction for such farmers. Diversification may occur as a deliberate household strategy or as an involuntary response to a crisis; and can be used both as a safety net for the rural poor or as a means of accumulation for the rural rich (Ellis, 1998).

Livelihood diversification as stated by Saha and Bahal (2010) is a continuous adaptive process whereby households add new activities, maintain existing ones or drop others, thereby maintaining diverse and changing livelihood portfolios. Livelihood diversification includes both onand off-farm activities which are undertaken to generate income additional to that from the main household agricultural activities, via the production of agricultural and non-agricultural goods and services, the sale of waged labour, or self-employment in small firms, and other strategies undertaken to spread risk. The agrarian sector 
of hill state, Meghalaya, India, in general, has witnessed a paradigm shift in the cropping pattern away from food crops towards non-food crops, and from one non-food crop to another non-food crop as to capture benefits of emerging markets. People diversify by adopting a range of activities. Until the 1990's, the economy of the state was almost completely agrarian, and farming was considered not as a traditional activity but an economic activity with a clear focus on higher productivity at all levels. Agricultural holdings are generally small and scattered; farming is often subsistence, characterized by simple tools and traditional methods of cultivation. The main purpose of this study is to identify the different diversified portfolio of activities that jointly determine the living gained of an individual or household in the village. It specifically aims to: (1) analyze the effect of livelihood diversification (2) measure the level of diversification, and (3) analyze the determinants influencing livelihood diversification.

\section{DATABASE AND METHODOLOGY}

The study was conducted in the Northeastern state of India, Meghalaya at Mawpran village. This village was selected purposively as it is an upcoming strawberry hub of the state where livelihood diversification is at a peak. Ninety farmers from the village were selected by simple random sampling method. A semi-structured questionnaire was developed and used for collecting the data from the farmer. The questionnaire was composed of open and closed questions and presented by using averages, frequencies, Wilcoxon signed rank test and linear regression. Diversification index was measured with the help of the Simpson index of diversity. The Simpson index of diversity is defined as:

$$
S I D=1-\sum_{i} P_{i}^{2}
$$

Where, $P_{i}$ as the proportion of income coming from source $i$. The value of SID always falls between 0 and 1. For least diversified households (i.e., those depending on a single income source) SID takes on its minimum value of 0 . The upper limit for SID is 1 which depends on the number of income sources available and their relative shares. The higher the number of income sources as well as more evenly distributed the income shares, the higher the value of SID. The Simpson Index of Diversity is affected both by the number of income sources as well as by the distribution of income between different sources (balance). The more uniformly distributed is the income from each source, the SID approaches to 1.

\section{RESULTS AND DISCUSSION}

\section{Temporal diversification across social categories}

Temporal diversification is a type of diversification where household members change from doing one activity to another with time. It can be observed from Table 1 that majority of the residence of the village who were marginal farmers diversified their occupational activities from on-farm traditional crops (broomsticks, vegetables) to non-farm activities (58.33\%) while 16.67 per cent did not diversified. Among the small farmers, the common diversification occurred from diversification from on-farm traditional crops (broomsticks, vegetables) to mixed farming (on \& off farming activities). Majority of the medium farmers $(53.85 \%)$ and large farmers $(66.67 \%)$ diversified from non-farm activities to on-farm high-value crop (strawberries). Many of the residents still rely on traditional crops like broom-sticks which grow wildly in and around the village although income generated from it is less. Being a suitable area for the high-value crop (strawberry), the majority of the residents who are resource-rich earned a large sum of income entirely from strawberries. It was observed that those residents in spite of cultivating high-value crops and vegetables had to cultivate broomsticks in a small portion of their land. From Table 1, we can also observe that majority of the respondents who were landless $(62.68 \%)$ did not diversified. Similar findings were also recorded by NSSO (2014) who found that 58 per cent of rural households in India were engaged in farming activity while more than half of the marginal farmers (56\%) who possess less than 0.01 hectare plot rely on sources like wages and non-farm-activities as principal source of income.

\section{Impact of diversification on material possession, livestock possession and income of the households}

Using non-parametric statistic test -Wilcoxon sign rank test, it can be observed from Table 2 
Table 1: Temporal diversifications across social categories who owned land $(n=90)$

\begin{tabular}{cccccc}
\hline Category & $\begin{array}{c}\text { Marginal farmers } \\
(\mathbf{n}=\mathbf{2 4})\end{array}$ & $\begin{array}{c}\text { Small farmers } \\
(\mathbf{n}=\mathbf{1 2})\end{array}$ & $\begin{array}{c}\text { Medium farmers } \\
(\mathbf{n}=\mathbf{1 3})\end{array}$ & $\begin{array}{c}\text { Large farmers } \\
(\mathbf{n}=\mathbf{6})\end{array}$ & $\begin{array}{c}\text { Landless } \\
(\mathbf{n}=\mathbf{3 5})\end{array}$ \\
\hline Case I & $14(58.33 \%)$ & 0 & 0 & 0 & 0 \\
Case II & $6(25.00 \%)$ & $6(50.00 \%)$ & 0 & 0 & 0 \\
Case III & 0 & 0 & $7(53.85 \%)$ & $4(66.67 \%)$ & 0 \\
Case IV & 0 & $4(33.33 \%)$ & $4(30.77 \%)$ & 0 & 0 \\
Case V & 0 & 0 & 0 & $2(33.33 \%)$ & 0 \\
Case VI & $4(16.67 \%)$ & $2(16.67 \%)$ & $2(15.38 \%)$ & 0 & $22(62.86 \%)$ \\
Case VII & 0 & 0 & 0 & 0 & $6(17.14 \%)$ \\
Case VIII & 0 & 0 & 0 & 0 & $7(20.00 \%)$ \\
\hline
\end{tabular}

$\checkmark$ Case I: Diversification from on-farm traditional crops (broomsticks, vegetables) to non-farm activities.

$\checkmark$ Case II: Diversification from on-farm traditional crops (broomsticks, vegetables) to mixed farming (on \& off farming activities).

$\checkmark$ Case III: Diversification from on-farm traditional crops (broomsticks, vegetables) to on-farm high value crops (strawberries).

$\checkmark$ Case IV: Diversification from non-farm activities to on-farm high value crop (strawberries).

$\checkmark$ Case V: Diversification from mixed farming to on-farm high value crop (strawberries).

$\checkmark$ Case VI: No diversification.

$\checkmark$ Case VII: Diversification from non-farm activities to on-farm traditional crops (broomsticks, vegetables)

$\checkmark$ Case VIII: Diversification from wage earning to transportation

Table 2: Effect of diversification on material possession, livestock possession and income of the households

$$
(n=90)
$$

\begin{tabular}{|c|c|c|c|c|c|}
\hline S1. No. & Particulars & Negative Ranks & Positive Ranks & Ties & Wilcoxon Signed Rank Test \\
\hline \multicolumn{6}{|c|}{ Land owners (n=55) } \\
\hline 1 & Material Possession & 0 & 50 & 5 & $6.16^{* *}$ \\
\hline 2 & Livestock Possession & 9 & 31 & 15 & $3.33^{*}$ \\
\hline 3 & Income & 5 & 50 & 0 & $5.510^{* *}$ \\
\hline \multicolumn{6}{|c|}{ Landless (n=35) } \\
\hline 1 & Material Possession & 0 & 31 & 4 & $4.86^{* *}$ \\
\hline 2 & Livestock Possession & 10 & 11 & 14 & 1.73 \\
\hline 3. & Income & 0 & 34 & 1 & $5.08^{* *}$ \\
\hline
\end{tabular}

(Significance $-{ }^{*} p<0.05,{ }^{* *} p<0.01$ ).

that diversification had a significant impact on the material possession and income level of both landowners and landless respondents. Positive ranks imply present situation after the diversification of the respondent was greater than the earlier situation without diversification and vice-versa for negative ranks while ties imply no difference was there between the earlier and present livelihood situation. Thus, diversification makes a smooth flow of income to the household and improves the living standard by reducing both predictable and unpredictable fluctuations. Predictable, seasonal fluctuations in income can be enhanced by combining enterprises and activities that generate returns during different times of the year.

\section{Distribution of respondents on the basis of Simpson Index of Diversity}

The Simpson Index of Diversity is widely used to measure the diversity. The distribution of extent of diversification among respondents is given in Table 3. The average diversification index of the respondents was 0.32. A high Diversification Index of more than 0.43 was observed in about fifty per cent of the respondents implying that a majority of the respondents diversified their livelihood activities. As it can be observed that many of the respondents were involved in diversified portfolios, like high-value crops, traditional crops, bee-keeping, livestock, etc. 
Table 3: Distribution of Diversification Index (SID) among the households $(n=90)$

\begin{tabular}{cccc}
\hline $\begin{array}{c}\text { Diversification } \\
\text { index level }\end{array}$ & Score range & $\begin{array}{c}\text { Frequency } \\
\begin{array}{c}\text { Percentage } \\
\text { (\%) }\end{array}\end{array}$ \\
\hline Low & Up to 0.15 & 12 & 13.30 \\
Moderate & 0.16 to 0.43 & 32 & 35.60 \\
High & More than 0.43 & 45 & 50.00 \\
Average Diversification Index & \multicolumn{2}{c}{0.32} \\
\hline
\end{tabular}

\section{Determinants of degree of livelihood diversification}

To identify the determinants of the household characteristics on degree of livelihood diversification in the study area, linear regression was conducted. The ' $p$ ' value was computed at 0.05 levels of significance. A perusal of Table 4 revealed that the variables such as family annual income, age, land owned, livestock possession had no significant impact on livelihood diversification while education and cosmo-politeness was highly significant for determinant of diversification. Thus, information is very vital for livelihood diversification as proper timely and access to information can assist farmers in decision-making related to demand, market, etc.

Table 4: Determinants of degree of livelihood diversification

\begin{tabular}{|c|c|c|c|c|}
\hline $\begin{array}{l}\text { S1. } \\
\text { No. }\end{array}$ & Variables & Coefficient & $\begin{array}{c}\text { Standard } \\
\text { error }\end{array}$ & p-value \\
\hline 1 & Age & -0.0089 & 0.005 & 0.141 \\
\hline 2 & Education & 0.0018 & 0.036 & $0.03^{*}$ \\
\hline 3 & $\begin{array}{c}\text { Family annual } \\
\text { income }\end{array}$ & 4.61 & 5.06 & 0.372 \\
\hline 4 & Land owned & -0.058 & 0.051 & 0.267 \\
\hline 5 & $\begin{array}{l}\text { Livestock } \\
\text { Possession }\end{array}$ & -0.0009 & 0.008 & 0.907 \\
\hline 6 & $\begin{array}{l}\text { Cosmo- } \\
\text { politeness }\end{array}$ & 0.0077 & 0.0018 & $0.002^{*}$ \\
\hline
\end{tabular}

Dependent variable: Degree of livelihood diversification (SID), $R^{2}$ $=40,{ }^{*} p<0.05$.

\section{CONCLUSION}

Livelihood diversification is an important feature of rural survival and in a general sense, a way of improving income level. Mixed farming which encompasses crop production and animal husbandry was the major source of livelihood in the study area. Diversified livelihood systems were able to provide more income for the household while farming still occupies a key position particularly in household food supply. Having income sources from non-farm activities makes a difference in overall income of smallholder farmers in the study area as it enables them to lessen the risk from farming. Our results show that some factors had positive effects on livelihood diversification, whereas others had negative effects; some were statistically significant at different significance levels while some others were not. The most significant factor determining livelihood diversification found was education, therefore professional training, access to information should be enhanced as to enable households to diversify their sources of income and thus improve their livelihood.

\section{REFERENCES}

Ellis, F. 1998. Household strategies and rural livelihood diversification. Journal of Development Studies, 35(1): 1-38.

Hiremath, B.N. 2007. The changing faces of rural livelihood in India, In: National Civil Society Conference on: What it Takes to Eradicate Poverty, held at Institute of Rural Management, Anand, 4-6 December.

Jirström, M., Andersson, A. and Djurfeldt, G. 2011. Smallholders caught in poverty - flickering signs of agricultural dynamism. In African Smallholders: food crops, markets and policy. (eds Djurfeldt et al.) London: CABI. Chapter 4, pp 74-106.

NSSO, 2014. Key indicators of Situation of Agricultural Households in India. Ministry of Statistics and Programme Implementation.

Saha, B. and Bahal, R. 2010. Livelihood diversification pursued by farmers in West Bengal. Indian Research Journal of Extension Education, 10(2): 1-9. 